\title{
JOHN MURRA Y LAS TALEGAS DE ISLUGA
}

\author{
Verónica Cereceda ${ }^{1}$
}

Cuando recibí la sugerencia de la Dirección del número de Chungara, dedicado a la memoria de John Murra, de incluir en esta publicación una versión castellana de "Semiología de los textiles andinos: las talegas de Isluga", me sentí muy conmovida, pero, al mismo tiempo, con gran pudor. ¿Por qué sería este texto, tan antiguo ya, un homenaje a John? Recordé, sin embargo, de inmediato, la relación directa que él tuvo con este artículo y me inundó un profundo agradecimiento, sintiendo vivamente todo lo que le debo.

En los años setenta realizamos un largo trabajo de campo, con mi esposo Gabriel Martínez, en el ayllu Isluga. Estaba ya interesada en los diseños de los textiles, pero, al mismo tiempo, una cierta reticencia me impedía dar forma a los datos que iba obteniendo al observar tantos tejidos y conversar con las tejedoras. ¿Cómo dar cuenta de la relación que formas y colores establecían con otros significados de la cultura? Los estudios andinos no estaban, por ese entonces, muy desarrollados en Chile y menos sobre un tema tan preciso como el diseño de unas simples bolsas de almacenaje. La información era fuerte, sin embargo, y me decidí a procesarla. El primer manuscrito recibió el estímulo de dos grandes amigos: Tristan Platt, que incluso redactó una reseña, y Jorge Hidalgo, que me comunicó su entusiasmo desde Arica. Ellos me sugirieron que se lo enviase a John Murra.

Con John nos habíamos conocido en 1973, en el Primer Congreso del Hombre Andino realizado entre Arica e Iquique, muy poco antes del golpe de estado en Chile. Desde entonces, nos escribíamos de vez en cuando. Cuando publicó "Las etnocategorías de un khipu estatal" me envió una nota breve, como acostumbraba muchas veces. $\mathrm{Su}$ pregunta era ¿por qué, en el khipu de los señores de Jatun Xauxa, las cuerdas anotaban inmediatamente después de los seres vivos (personas y ganado), a los tejidos dados en tributo? Los tejidos antes que el maíz, antes que las papas. Mi respuesta fue, tres años después, el texto de las talegas. Y recibí otra nota breve: "¡De modo que las talegas son, también, animales!", es decir, son seres vivo. Y desde entonces, John decidió el destino de ese texto: no sólo lo publicó en el número de Annales que dirigió junto a Nathan Wachtel, en 1978, sino que quiso hacer directamente él la traducción del francés al inglés -y se dio el trabajo de hacerlo-para la edición de Anthropological History of Andean Polities de Cambridge University Press.

Esas ediciones, entre otros factores, y el apoyo de John, posibilitaron nuestra beca en la Pontificia Universidad Católica de Lima para estudiar un Magíster en Antropología y posteriormente un doctorado en la École des Hautes Études en Sciences Sociales, en París.

Esos recuerdos me vinieron con la solicitud de publicar "Semiología de los textiles andinos: las talegas de Isluga", ahora por primera vez en castellano $^{1}$. Sin embargo, lo que recuerdo con más fuerza, y día a día, es su presencia encantadora y siempre estimulante, sea en París, en Lima, en Santiago, en Bolivia. Quizás no hay ya nadie como él hoy, tan dedicado a impulsar los estudios andinos no sólo siendo un lector atento, sino a través de gestiones, cartas, publicaciones, que él se daba la molestia de llevar adelante para desarrollar los trabajos de otros colegas. Muchos somos los que estamos en deuda con su pasión y su amistad calurosa.

Hasta muy cerca de su muerte seguí recibiendo pequeñas notas, a veces la fotocopia de un artículo que le parecía interesante, a veces sólo unas palabras sobre un trozo de papel. Lo último que me llegó fue su escritura sobre una página de un periódico de Madrid, que hablaba sobre un fotógrafo. Con su letra firme me puso, en grandes caracteres: “¿Sabías que en España hay un fotógrafo que se llama Cerecedo? Así, con "o." Humor y cariño, tan propios de él.

Sucre, febrero, 2008

1 Fundación para la Investigación Antropológica y el Etnodesarrollo "Antropólogos del Surandino", ASUR. Sucre, Bolivia. veronicacereceda@gmail.com 


\section{Nota}

1 Nota del Editor: Este manuscrito circuló en forma de fotocopia, desde principios de la década de 1970, pero nunca tuvo una edición e impresión formal, puesto que su publicación fue censurada en la edición del Volumen 8 de Chungara en 1981. 